\title{
FORMAÇÃO DE PALHADA POR BRAQUIÁRIAS PARA ADOÇÃO DO SISTEMA PLANTIO DIRETO $\left({ }^{1}\right)$
}

\author{
PAULO CÉSAR TIMOSSI ( $\left.{ }^{2}\right)$; JULIO CEZAR DURIGAN $\left(3^{*}\right)$; GILSON JOSÉ LEITE $\left({ }^{4}\right)$
}

\begin{abstract}
RESUMO
Com o objetivo de avaliar espécies forrageiras para formação de palhada para adoção do sistema plantio direto, foi pesquisado o potencial de Brachiaria decumbens e B. brizantha, comparadas ao milheto (Pennisetum glaucum). As plantas de cobertura foram semeadas em março e conduzidas até novembro (momento do manejo químico). Aos 50, 110 e 250 dias após a semeadura (DAS) foram avaliadas a composição específica das infestantes na cobertura vegetal, a porcentagem visual de cobertura do solo e o acúmulo de massa vegetal seca das coberturas. As braquiárias foram eficientes na formação de palha (acima de 11 tha $^{-1}$ ), sendo promissoras para o sistema plantio direto. Também, observou-se densa cobertura do solo, com supressão do desenvolvimento de plantas daninhas, o que não se percebeu com milheto, cujo maior potencial de cobertura do solo e acúmulo $\left(10,5 \mathrm{t} \mathrm{ha}^{-1}\right)$ de massa ocorreu no fim do seu ciclo (110 DAS) e, 3,2 t ha ${ }^{-1}$ de massa vegetal seca aos 250 DAS. Devido à rápida decomposição da palha de milheto observou-se, também, reinfestação da área por plantas daninhas.
\end{abstract}

Palavras-chave: Cobertura vegetal, planta daninha, Brachiaria brizantha, Brachiaria decumbens, Pennisetum glaucum.

\section{ABSTRACT \\ STRAW FORMATION BY BRACHIARIA SPECIES TO ADOPTION OF NO-TILLAGE SYSTEM}

With the objective of testing pasture species for formation of straw to initiate a no-tillage system, the potential of Brachiaria decumbens and B. brizantha was studied and compared to millet Pennisetum glaucum. Cover crops were sown on March and conducted until November (time of the chemical management). At 50, 110 and 250 days after sown (DAS) the specific composition of weeds on the cover crops, the visual percentage of the soil cover and the accumulated dry mass of cover crops were evaluated. Brachiaria species were efficient on straw formation (around $11 \mathrm{t} \mathrm{ha}^{-1}$ ), showing larger production than other species recommended for no-tillage. Also, they presented dense soil covering with suppression of weed development. This was not observed with Pennisetum glaucum, that showed its major potential of soil covering and accumulated dry mass $\left(10.5 \mathrm{t} \mathrm{ha}^{-1}\right)$ at the end of the cycle (110 DAS) and $3.2 \mathrm{t} \mathrm{ha}^{-1} \mathrm{of} \mathrm{dry}$ mass at 250 DAS. Due to the fast millet straw decomposition, weed reinfestation was also observed.

Key words: Cover crops, weed, Brachiaria decumbens, Brachiaria brizantha, Pennisetum glaucum.

$\left({ }^{1}\right)$ Recebido para publicação em 3 de fevereiro de 2006 e aceito em 11 de junho de 2007.

$\left({ }^{2}\right)$ Engenheiro Agrônomo, Doutor em Produção Vegetal pela FCAV/UNESP Jaboticabal. E-mail: ptimossi2004@yahoo.com $\left(^{*}\right)$ Autor correspondente.

$\left({ }^{3}\right)$ Departamento de Fitossanidade, FCAV/UNESP, Via de Acesso Prof. Paulo Donato Castellane, km 05, s/n., Jaboticabal (SP). E-mail: jdurigan@fcav.unesp.br

$\left({ }^{4}\right)$ Técnico Agrícola, Departamento de Fitossanidade, FCAV/UNESP, Jaboticabal (SP). E-mail: gilsonjleite@yahoo.com.br 


\section{INTRODUÇÃO}

$\mathrm{Na}$ adoção do plantio direto, a boa formação de cobertura vegetal na superfície do solo antes da implantação da cultura é requisito indispensável (Almeida, 1991; Alvarenga et al., 2001). No entanto, a escolha adequada das plantas fornecedoras da palhada, considerando-se a melhor época de semeadura, tem sido o grande entrave para se obter êxito com o sistema em diferentes regiões, pois ocorrem grandes variações no clima e no solo (ANDRIOLI, 2004).

No Brasil, nas regiões Sudeste, Centro-Oeste e parte do Nordeste, o clima é caracterizado por um inverno seco, com encurtamento do fotoperíodo, o que dificulta o estabelecimento de plantas nesta época do ano. Desse modo, o estabelecimento de uma cobertura do solo com plantas semeadas para essa finalidade, em março e abril, têm-se constituído no maior desafio para o sistema na região do Cerrado e adjacências (Alvarenga et al., 2001).

Se por um lado a aveia é apontada como a cultura responsável pela expansão do plantio direto na Região Sul do país, o milheto cumpriu esse papel na região Central (SALTON, 2001). Recentemente, o uso de espécies forrageiras como as do gênero Brachiaria para a formação de palha, vêm despertando o interesse de agricultores e pesquisadores (APDC, 2001; BERNARDES, 2003; TorRes, 2003; ANDRIOLI, 2004). Estas forrageiras são de grande potencial na manutenção da palha sobre o solo devido a sua relação $\mathrm{C} / \mathrm{N}$ alta, o que retarda sua decomposição e aumenta a possibilidade de utilização em regiões mais quentes. Nas regiões de clima tropical, trabalhos de pesquisa têm demonstrado que a maior limitação, na manutenção de palha sobre o solo, é a rapidez com que a massa vegetal se decompõe (Pereira, 1990; LANDERS, 1995).

A braquiária se destaca pela excelente adaptação a solos de baixa fertilidade, fácil estabelecimento e considerável produção de biomassa durante o ano, proporcionando excelente cobertura vegetal do solo. Segundo Bernardes (2003), esta forrageira já é difundida e aceita pelos produtores rurais, o que facilita a sua eventual adoção para a produção de massa para a cobertura do solo, em sistema plantio direto. No entanto, PelÁ (2002) e
TORRes (2003) verificaram pequeno acúmulo de massa vegetal pela $B$. brizantha semeada na primavera.

O objetivo deste trabalho foi avaliar o desenvolvimento de Brachiaria decumbens e $B$. brizantha visando à formação de massa vegetal para cobertura morta em áreas de plantio direto, quando semeadas no outono, após a colheita da cultura de verão, comparadas ao milheto.

\section{MATERIAL E MÉTODOS}

O experimento foi desenvolvido entre março e novembro de 2003, em área experimental pertencente à Faculdade de Ciências Agrárias e Veterinárias da Universidade Estadual Paulista - UNESP, Câmpus de Jaboticabal. O solo foi classificado como Latossolo Vermelho, textura argilosa e relevo suave (EMBRAPA, 1999). Antecedendo a semeadura foi feita análise química do solo, de amostras retiradas à profundidade de zero a $0,20 \mathrm{~m}$ e de 0,20 a $0,40 \mathrm{~m}$ (Tabela 1), seguindo método de RaIj et al. (2001).

O delineamento experimental utilizado foi o de blocos casualizados, com os tratamentos sendo formados por três espécies vegetais, com oito repetições. As espécies usadas como plantas de cobertura foram capim-braquiária (Brachiaria decumbens - BRADC), braquiarão (Brachiaria brizantha - BRABR) e milheto (Pennisetum glaucum - PESGL). Estas espécies foram semeadas em parcelas de $300 \mathrm{~m}^{2}(6 \mathrm{~m} \times 50 \mathrm{~m})$.

A semeadura foi feita no início de março de 2003, a lanço, na quantidade de $20 \mathrm{~kg}$ de sementes por hectare para cada espécie. O valor cultural (VC) das sementes das braquiárias era de $40 \%$ e as sementes de milheto, de $70 \%$ de germinação.

O preparo da área experimental constou de uma aração e duas gradagens leves. Imediatamente após a distribuição das sementes das espécies usadas para as coberturas vegetais foi realizada uma gradagem leve, com o uso de grade niveladora de arrasto, destravada. No Brasil, segundo ZIMMER et al. (1992), a semeadura de $B$. decumbens deve ser realizada à profundidade de 2 a $4 \mathrm{~cm}$, o que foi obtido no presente estudo. Devido ao solo do local ser de fertilidade suficiente para uma possível adoção do sistema plantio direto, não houve necessidade da aplicação de calcário.

Tabela 1. Resultados da análise química do solo da área experimental

\begin{tabular}{lcccccccccc}
\hline Prof. & $\mathrm{pH}$ & $\mathrm{MO}$ & $\mathrm{P}$ resina & $\mathrm{K}^{+}$ & $\mathrm{Ca}^{+2}$ & $\mathrm{Mg}^{+2}$ & $\mathrm{H}^{+}+\mathrm{Al}^{+3}$ & $\mathrm{SB}$ & $\mathrm{T}$ & $\mathrm{V}$ \\
\cline { 1 - 5 } $\mathrm{cm}$ & $\mathrm{CaCl}_{2}$ & $\mathrm{~g} \mathrm{dm}^{-3}$ & $\mathrm{mg} \mathrm{dm}{ }^{-3}$ & & & $\mathrm{mmol}_{\mathrm{c}} \mathrm{dm}^{-3}$ & & & \\
$0-20$ & 5,8 & 22 & 40 & 5,8 & 33 & 14 & 21 & 52,8 & 73,8 & 71 \\
$20-40$ & 5,6 & 16 & 13 & 4,3 & 26 & 13 & 20 & 43,3 & 63,3 & 68 \\
\hline
\end{tabular}


Aos 50 dias após a semeadura (DAS), foi feita contagem do número de plantas obtidas na área delimitada por um retângulo metálico de $0,5 \mathrm{~m} \times 1,0 \mathrm{~m}$, lançado por duas vezes em cada parcela. Após a contagem, foi realizada a coleta da massa vegetal proveniente da parte aérea das plantas, acondicionadas em sacos de papel e colocadas à câmara de circulação de ar a temperatura de $60^{\circ} \mathrm{C}$, durante 72 horas e sendo posteriormente pesadas. Também foi determinada a densidade da comunidade pela contagem do número de plantas de cobertura e daninhas. Nesta época, também foi realizada por dois pesquisadores da área, a avaliação visual da porcentagem de cobertura do solo pelas plantas de cobertura e demais espécies de plantas daninhas presentes, baseando-se em escala de 0 a 100.

Aos 110 DAS foi feita coleta de massa vegetal, utilizando a mesma metodologia citada na primeira avaliação sem, no entanto, realizar a contagem do número de plantas, devido à dificuldade de separálas, principalmente as braquiárias, pelo alto índice de perfilhamento e cobrir totalmente a área. Novamente foi feita avaliação visual da porcentagem de cobertura do solo pela massa vegetal e sua respectiva composição específica. O mesmo procedeu-se aos 250 DAS, quando do manejo químico das coberturas (novembro), com a dessecação por herbicidas de manejo das plantas de cobertura e preparação para a realização da semeadura de culturas de verão.

As médias mensais de temperatura média do ar e o total das precipitações pluviais ocorridas durante $o$ período experimental estão apresentados na figura 1.

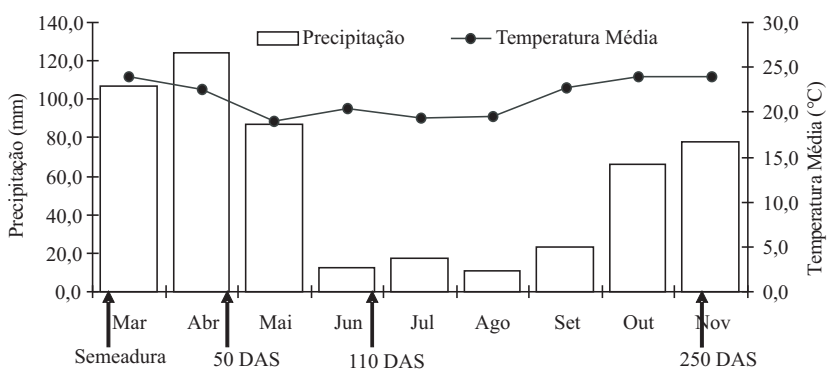

Figura 1. Médias mensais de temperatura média do ar e total de precipitações pluviométricas, ocorridas durante o experimento.

Apenas os dados de massa vegetal das coberturas vegetais foram submetidos ao teste $F$ para a análise de variância e ao teste de Tukey ao nível de $5 \%$ de probabilidade para a comparação das médias.

\section{RESULTADOS E DISCUSSÃO}

A formação de cobertura morta no solo por espécies vegetais é dependente do bom estabelecimento inicial das plantas, densidade populacional e da biomassa produzida.
As densidades das plantas de cobertura em estudo (Tabela 2) foram próximas entre as braquiárias e estas inferiores às obtidas para o milheto, quando avaliadas aos 50 DAS. Embora tenham sido semeadas quantidades iguais $\left(20 \mathrm{~kg} \mathrm{ha}^{-1}\right)$ de sementes para os três tipos de cobertura, infere-se que o tamanho das sementes e suas características endógenas, relacionadas à dormência, levaram aos diferentes números de plantas emergidas.

VALLE et al. (2000) recomendam, para a formação exclusiva de pastagens, pelo menos 15 a 20 plântulas de Brachiaria decumbens por $\mathrm{m}^{2}$ nos primeiros 60 a 90 dias após a semeadura. As densidades populacionais das braquiárias, embora inferiores às obtidas com o milheto, foram muito superiores à recomendada pelos autores. Essas altas densidades de plantas constatadas na semeadura das braquiárias não foram suficientes para suprimir a presença de espécies de plantas daninhas oriundas do banco de sementes do solo, levando-as à competição interespecífica.

As principais espécies que conviveram com as plantas de cobertura foram losna-branca (Parthenium hysterophorus - PTNHY), capim-carrapicho (Cenchrus echinatus - CCHEC), apaga-fogo (Alternanthera tenella - ALRTE) e outras em menor quantidade como trapoeraba (Commelina benghalensis - COMBE), anileira (Indigofera hirsuta - INDHI) e caruru (Amaranthus hibridus e A. retroflexus).

O fator responsável pela maior porcentagem de infestação da comunidade infestante foi, provavelmente, o desenvolvimento inicial lento das braquiárias, especialmente da $B$. brizantha que conviveu com maior número de plantas de capimcarrapicho aos 50 DAS. PeLÁ (2002) afirmou que essa infestação inicial por plantas daninhas em $B$. brizantha, por causa do desenvolvimento lento, dificulta o estabelecimento e promove baixo acúmulo de massa vegetal, quando plantada na primavera.

O milheto, nesta época de avaliação (50 DAS), já estava em início de formação de panículas e distribuição uniforme devido à sua alta densidade na área. Pode-se observar que, devido ao seu rápido crescimento e maior número de plantas emergidas, ocorreu ação supressora, impedindo a emergência, em grandes quantidades, de plantas da comunidade infestante. Segundo Burger (1984), a maioria das cultivares de milheto se beneficiam com o fotoperíodo do outono/inverno, uma vez que se trata de espécie de dia curto. Lemos et al. (2003) avaliaram o desenvolvimento do milheto semeado em época semelhante ao do presente estudo e verificaram que, em torno de dois meses, também houve emissão de panículas. 
Tabela 2. Densidades populacionais das plantas de cobertura estudadas e respectivas infestantes na área experimental, avaliadas aos 50 dias após a semeadura

\begin{tabular}{|c|c|c|c|c|c|c|}
\hline \multirow{3}{*}{ Espécies } & \multirow{2}{*}{\multicolumn{2}{|c|}{$\frac{\text { BRADC }\left({ }^{1}\right)}{\text { plantas }}$}} & \multirow{2}{*}{\multicolumn{2}{|c|}{$\frac{\text { BRABR }\left(^{2}\right)}{\text { plantas }}$}} & \multirow{2}{*}{\multicolumn{2}{|c|}{$\frac{\text { PESGL }\left({ }^{3}\right)}{\text { plantas }}$}} \\
\hline & & & & & & \\
\hline & $\mathrm{m}^{-2}$ & $\%\left({ }^{7}\right)$ & $\mathrm{m}^{-2}$ & $\%$ & $\mathrm{~m}^{-2}$ & $\%$ \\
\hline & 208,6 & 56,9 & 158,6 & 47,6 & 563,6 & 94,3 \\
\hline PTNHY $\left({ }^{4}\right)$ & 53,6 & 14,6 & 47,2 & 14,2 & 18,6 & 3,1 \\
\hline $\mathrm{CCHEC}\left({ }^{5}\right)$ & 55,6 & 15,2 & 102,0 & 30,6 & 1,6 & 0,3 \\
\hline $\operatorname{ALRTE}\left({ }^{6}\right)$ & 23,6 & 6,4 & 16,2 & 4,9 & 14,0 & 2,3 \\
\hline Outras & 25,4 & 6,9 & 9,2 & 2,8 & 0,0 & 0,0 \\
\hline Total & 366,8 & 100,0 & 333,2 & 100,0 & 597,8 & 100,0 \\
\hline
\end{tabular}

$\left({ }^{1}\right)$ Brachiaria decumbens. $\left({ }^{2}\right)$ Brachiaria brizantha. $\left({ }^{3}\right)$. Pennisetum glaucum. $\left({ }^{4}\right)$ Parthenium hysterophorus; $\left({ }^{5}\right)$ Cenchrus echinatus. $\left({ }^{6}\right)$ Alternanthera tenella; $\left({ }^{7}\right)$ Porcentagem de infestação na área avaliada.

Na figura 2A é apresentada a porcentagem de cobertura do solo pela massa vegetal de $B$. decumbens e demais espécies de plantas da comunidade infestante nas três épocas avaliadas. Aos 50 DAS, constatou-se a maior porcentagem de infestação de plantas daninhas, mostrando haver interferência no estabelecimento da planta de cobertura. Nota-se que, ao longo das avaliações, a $B$. decumbens aumentou sua porcentagem de cobertura do solo, até atingir 100\%, mostrando ser espécie com grande capacidade competitiva. Na época do manejo químico (250 DAS), para a formação da cobertura morta, não havia a presença expressiva da massa vegetal oriunda das plantas daninhas que compunham a comunidade infestante inicial.

A porcentagem de cobertura do solo pela massa vegetal de $B$. brizantha e demais espécies de plantas da comunidade infestante seguiu a mesma tendência (Figura 2B). Verificou-se que a cobertura do solo proporcionada por B. brizantha, aos 50 DAS, foi ao redor de $45 \%$, aumentando para $80 \%$ aos 110 DAS e $100 \%$ aos 250 DAS. Assim, pode-se afirmar que, apesar do desenvolvimento inicial lento desta gramínea, o bom estande inicial fez com que fosse capaz de competir e dominar totalmente o espaço, formando uma cobertura vegetal uniforme, sem infestantes, na época do seu manejo. As braquiárias são originárias de pradarias africanas, sendo consideradas plantas-clímax com grande capacidade competitiva, o que lhes conferiu total ocupação da área. Esse processo ocorreu, também, em decorrência de as espécies que compunham a comunidade infestante eram, em sua maioria, de ciclo anual, com senescência natural dentro do período considerado.

Na figura 2C é apresentada a porcentagem de cobertura do solo pela massa vegetal de $P$. glaucum e demais espécies de plantas da comunidade infestante.
O rápido desenvolvimento inicial de milheto proporcionou, aos $50 \mathrm{DAS}$, cobertura total do solo, suprimindo a formação de massa vegetal pelas poucas plantas daninhas existentes das espécies que compunham a comunidade infestante. Aos 110 DAS, o milheto estava no fim de ciclo, com a liberação de sementes pela 'degrana', sobre o solo. A partir desta época, as plantas das espécies que coabitavam na área, sem formação expressiva de massa vegetal, somaram-se a novas, provenientes do banco de sementes do solo, e passaram a ter maior importância na porcentagem de cobertura do solo.

Aos 250 DAS, a cobertura do solo proporcionada pela massa vegetal viva era composta de losna-branca, capim-carrapicho, apaga-fogo e outras com menor expressão como caruru, anileira, corda-de-viola e trapoeraba. Embora a vegetação espontânea cobrisse totalmente o solo, constatava-se distribuição desuniforme das populações e plantas em diversos estádios de desenvolvimento. Segundo SCALÉA (1997), a formação de cobertura vegetal com vários extratos, como é o caso da vegetação espontânea, proporciona complicações como a perenização de algumas espécies e abundante produção de sementes por outras, dificultando a ação dos herbicidas.

Apesar de ter sido constatada a degrana das plantas de milheto no fim do ciclo, com a liberação de grande quantidade de sementes sobre o solo, não houve germinação de novas plantas e a porcentagem de cobertura vegetal proporcionada pela emergência de plantas desta espécie foi inexpressiva por época do manejo. Kissmann e Groth (1997) afirmam que, dependendo da cultivar, pode haver dormência das sementes logo após a maturação, que pode estenderse por até 12 meses, aumentando o risco de tornar-se infestante de culturas. 

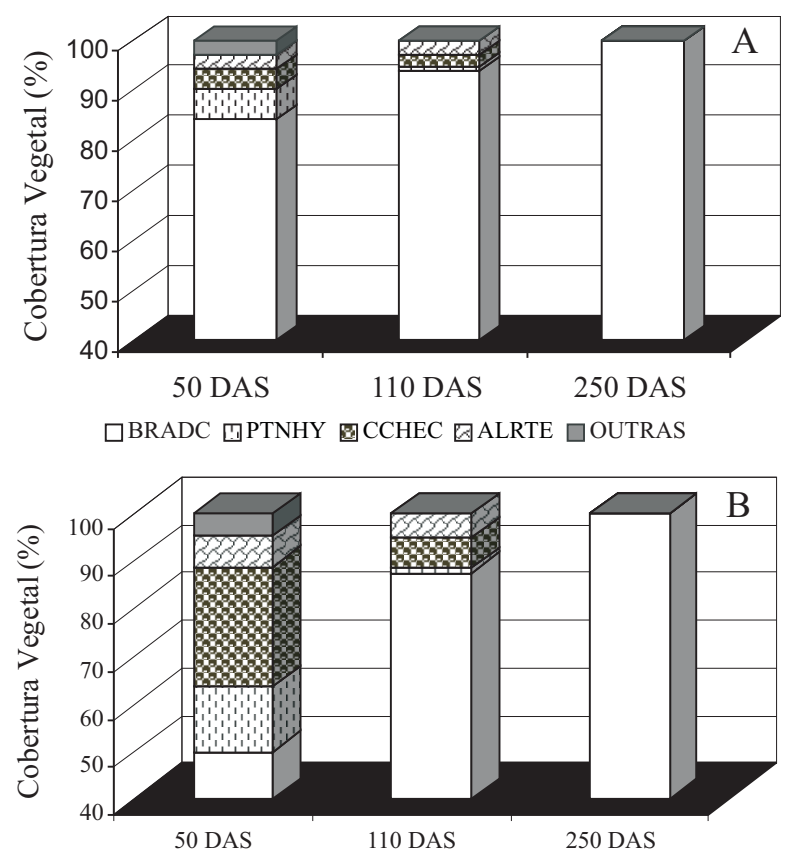

$\square$ BRABR 四PTNHY 图CCHEC $⿴$ ALRTE $\square$ OUTRAS

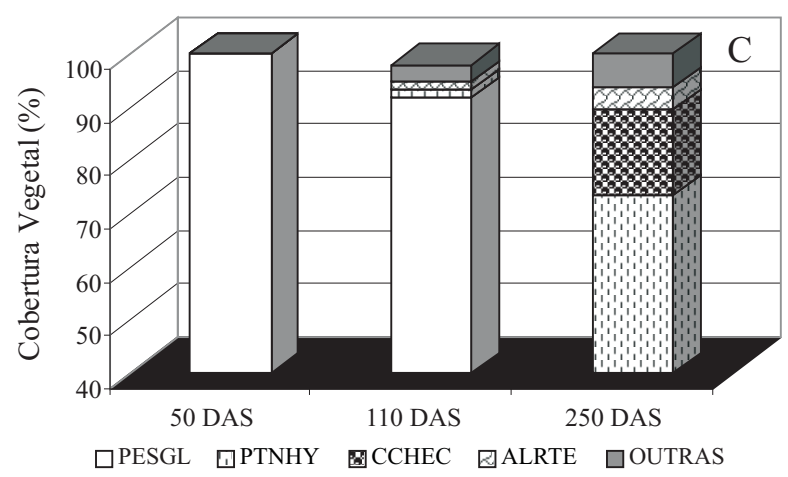

Figura 2. Evolução percentual da cobertura vegetal proporcionada por Brachiaria decumbens - BRADC (A), Brachiaria brizantha - BRABR (B), Pennisetum glaucum PESGL (C), losna-branca - PTNHY, capim-carrapicho CCHEC e apaga-fogo - ALRTE, quando em convivência, aos 50, 110 e 250 dias após a semeadura (DAS).

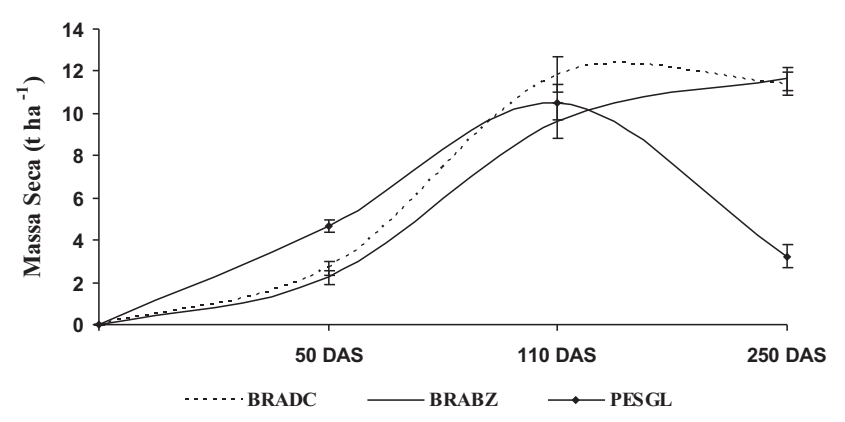

Figura 3. Acúmulo de massa seca da parte aérea de Brachiaria decumbens - BRADC; Brachiaria brizantha BRABR; Pennisetum glaucum - PESGL acrescidas da massa vegetal produzida pela comunidade infestante presente.
Moraes (2001) destaca que a maior aceitação do sistema plantio direto está relacionada à quantidade e à qualidade da palhada produzida pelas plantas de cobertura. Além das características citadas pelo autor, deve-se atentar para a longevidade do ciclo de vida das plantas de cobertura.

Na figura 3, é apresentado o acúmulo de massa vegetal seca, nas três situações caracterizadas anteriormente, aos 50, 110 e 250 DAS. Entre a primeira e segunda épocas avaliadas, houve maior taxa de produção de massa seca, para todos os tipos de cobertura em estudo. A partir desta época, e devido ao fim de seu ciclo, o milheto iniciou decomposição da sua palha, consumindo parte da massa vegetal seca acumulada.

A massa acumulada até aos 110 DAS foi ao redor de 10,7 t ha ${ }^{-1}$, para as plantas de cobertura em estudo, com tendência de maior acúmulo para a $B$. decumbens. A produção de massa seca de Brachiaria brizantha diferiu estatisticamente da produção obtida com $B$. decumbens, comprovando o crescimento mais lento dessa espécie.

Trabalhos realizados por Pelá (2002) e TORRES (2003), relacionaram o menor acúmulo de massa vegetal promovido pela $B$. brizantha, quando semeada na primavera, ao curto espaço de tempo para o crescimento. No presente estudo, notou-se que as braquiárias semeadas no outono tiveram tempo suficiente para desenvolver e atingir, por época do manejo químico (250 DAS) realizado em novembro, produção de massa seca semelhante, com cobertura vegetal pura, ou seja, sem a presença da comunidade infestante.

A partir dos 110 DAS, pode-se verificar que o acúmulo de massa vegetal seca proporcionado pelas braquiárias, ficou sem aumento expressivo até 250 DAS, embora a $B$. brizantha tenha continuado a crescer. Perante o comportamento das braquiárias, quanto ao acúmulo de massa vegetal seca e considerando que uma cobertura morta ao redor de $6 \mathrm{t} \mathrm{ha}^{-1}$, que, segundo AlvARENGA et al. (2001) já seria suficiente para cobrir totalmente o solo, pode-se afirmar que áreas agrícolas com a adoção de tais plantas poderiam ser disponibilizadas para o pastoreio, sem perdas para o sistema, desde que haja bom manejo, evitando-se o rebaixamento excessivo da cobertura vegetal, com prejuízo aos rebrotes.

Na época do manejo químico (250 DAS), pôdese constatar que a massa vegetal seca proporcionada pelas braquiárias ao redor de $11,5 \mathrm{t} \mathrm{ha}^{-1}$, foi superior à oriunda da área onde havia milheto mais a vegetação natural, cerca de 3,2 t ha-1. Observou-se também, a semelhança na produção de massa seca pelas braquiárias. Segundo СовUCсі (2001), o plantio direto dependerá, para a sua evolução, de fontes eficientes de cobertura morta com longevidade adequada. 
Essa característica, segundo o autor, é garantida com as forrageiras do gênero Brachiaria, as quais têm produzido, quando bem manejadas, acima de $15 \mathrm{t} \mathrm{ha}^{-1}$ de biomassa seca e persistem por mais de seis meses na superfície do solo.

Para as condições entre outono e primavera, período em que ocorreram as plantas de cobertura do presente experimento, as plantas do gênero Brachiaria, foram boa alternativa para adoção do sistema plantio direto, pois são perenes e chegam à época do manejo com boa quantidade de massa vegetal e de grande durabilidade.

\section{CONCLUSÕES}

1. Para as condições climáticas em que foi desenvolvido o experimento, as coberturas vegetais proporcionadas pelas braquiárias (B. decumbens e $B$. brizantha) garantiram maior acúmulo de massa vegetal seca, acima de $11 \mathrm{tha}^{-1}$, na época do manejo químico.

2. O milheto ( $P$. glaucum) proporcionou boa cobertura do solo, com ciclo curto de desenvolvimento e não evitou o surgimento de plantas daninhas com a rápida decomposição da massa vegetal seca a partir da morte das plantas.

\section{REFERÊNCIAS}

ALMEIDA, F.S. Controle de plantas daninhas em plantio direto. Londrina: Instituto Agronômico do Paraná, 1991. 34p. (Circular, 67)

ALVARENGA, R.C.; CABEZAS, W.A.L.; CRUZ, J.C.; SANTANA, D.P. Plantas de cobertura de solo para sistema de plantio direto. Informe Agropecuário, Belo Horizonte, v. 22, n. 208, p. 25-36, 2001.

ANDRIOLI, I. Plantas de cobertura em pré-safra à cultura do milho em plantio direto, na região de Jaboticabal-SP. 2004. 78f. Tese (Livre-Docente) - Faculdade de Ciências Agrárias e Veterinárias, Universidade Estadual Paulista, Jaboticabal. 2004.

APDC- Associação de Plantio Direto no Cerrado. Braquiária mais que pasto II. Brasília, 2001. p.4. (Boletim Informativo, 6)

BERNARDES, L.F. Semeadura de capim-braquiária em pósemergência da cultura do milho para obtenção de cobertura morta em sistema de plantio direto. 2003. 42f. Dissertação (Mestrado em Agronomia) - Faculdade de Ciências Agrárias e Veterinárias - UNESP, 2003.

BURGER, A.W. Crop classification. In: TESAR, M.B. (Ed.). Physiological basis of growth and development. Madison: American Society of Agronomy, 1984. p.1-12.

COBUCCI, T. Manejo integrado de plantas daninhas em sistema plantio direto. In: ZAMBOLIM, L. (Ed.). Manejo integrado fitossanidade: cultivo protegido, pivô central e plantio direto. Viçosa: UFV, 2001. p.583-624.
EMPRESA BRASILERIA DE PESQUISA AGROPECUÁRIA. Sistema brasileiro de classificação dos solos. Brasília: EMBRAPA-SPI, Centro Nacional de Pesquisa de Solos, 1999. 412p.

KISSMANN, K. G.; GROTH, D. Plantas infestantes e nocivas. 2.ed. São Paulo: BASF, 1997. 825p. Tomo I

LANDERS, F. N. Fascículo de experiências de plantio direto no cerrado. Goiânia: APDC, 1995. 261p.

LEMOS, L.B.; NAKAGAWA, J.; CRUSCIOL, C.A.C.; CHIGNOLIJUNIOR., W.; SILVA, T.R.B. da. Influência da época de semeadura e do manejo da parte aérea de milheto sobre a soja em sucessão em plantio direto. Bragantia, Campinas, v. 62, n. 3, p. 405-415, 2003.

MORAES, R.N.S. Decomposição das palhadas de sorgo e milheto, mineralização de nutrientes e seus efeitos no solo e na cultura do milho em plantio direto. 2001, 90f. Dissertação (Mestrado em Agronomia) - Universidade Federal de Lavras - UFLA, Lavras, 2001.

PELÁ, A. Uso de plantas de cobertura em pré-safra e seus efeitos nas propriedades físicas do solo e na cultura do milho em plantio direto na região de Jaboticabal-SP. 2002, 53f. Dissertação (Mestrado em Agronomia) - Faculdade de Ciências Agrárias e Veterinárias de Jaboticabal - UNESP, 2002.

PEREIRA, F.A.R. Cultivo de espécies visando a obtenção de cobertura vegetal do solo na entressafra da soja (Glycine max L. Merril) no cerrado. 1990. 83f. Dissertação (Mestrado em Agricultura) - Faculdade de Ciências Agronômicas, Universidade Estadual Paulista, Botucatu, 2002.

SALTON, J.C. O plantio direto no Brasil. In: SEMINÁRIO INTERNACIONAL SOBRE PLANTIO DIRETO NOS TRÓPICOS SUL-AMERICANOS, 1., 2001, Dourados. Anais... Dourados: Embrapa Agropecuária Oeste, 2001. p.13-15.

RAIJ, B. van; ANDRADE, J.C.; CANTARELLA, H.; QUAGGIO, J.A. (Ed.). Análise química para a avaliação da fertilidade de solos tropicais. Campinas: Instituto Agronômico, 2001. 258p.

SCALÉA, M.J. Experiências do manejo de plantas daninhas nas condições do cerrado. In: CONGRESSO BRASILEIRO DA CIÊNCIA DAS PLANTAS DANINHAS, 21., 1997, CaxambuMG. Palestras e Mesas redondas... Viçosa: Sociedade Brasileira da Ciência das Plantas Daninhas, 1997. p.29-31.

TORRES, J.L.R. Estudo de plantas de cobertura na rotação milho-soja em sistema de plantio direto no cerrado, na região de Uberaba-MG. 2003. 108f. Tese (Doutorado em Agronomia) - Faculdade de Ciências Agrárias e Veterinárias, Universidade Estadual Paulista, Jaboticabal-SP.

VALLE, C. B.; EUCLIDES, V. P. B.; MACEDO, M. C. M. Características das plantas forrageiras do gênero Brachiaria. In: SIMPÓSIO SOBRE MANEJO DA PASTAGEM, 17., 2000, Piracicaba. Anais... Piracicaba: FEALQ, 2000. p. 65-108.

ZIMMER, A. H.; PIMENTEL, D. M.; VALLE, C. B.; SEIFFERT, N. F. Aspectos práticos ligados à formação de pastagens. 4.reimp. Campo Grande: EMBRAPA-CNPGC, 1992, 42p. (Circular Técnica, 12) 